\title{
Transition to work roles among youth in Rajasthan
}

International Institute for Population Sciences (IIPS)

Population Council

Follow this and additional works at: https://knowledgecommons.popcouncil.org/departments_sbsr-pgy

Part of the Demography, Population, and Ecology Commons, Family, Life Course, and Society Commons, International Public Health Commons, and the Medicine and Health Commons How does access to this work benefit you? Let us know!

\section{Recommended Citation}

International Institute for Population Sciences (IIPS) and Population Council. 2009. "Transition to work roles among youth in Rajasthan," Youth in India: Situation and Needs Policy Brief no. 25. Mumbai: IIPS.

This Brief is brought to you for free and open access by the Population Council. 


\section{Transition to work roles among youth in Rajasthan}

\begin{abstract}
"Achieving full and productive employment and decent work for all, including women and young people" is one of the targets articulated under the Millennium Development Goals and ratified by countries worldwide, including India. ${ }^{a}$ Also, reflecting India's commitment to meeting the employment needs of its citizens, new policy and programmatic initiatives have been launched in the country in recent years. For example, the Draft National Employment Policy aims to achieve "remunerative and decent employment for all women and men in the labour force"; and the recently approved National Policy on Skill Development (2009) aims to empower individuals, especially youth and women, through improved skills, knowledge and qualifications to gain access to employment in an increasingly competitive global market. It is important, in this context, to take stock of the extent to which youth are equipped to make a successful transition to work roles and the extent to which they are indeed making that transition; this policy brief aims to do so for the state of Rajasthan. Specifically, are youth in the state transitioning into work roles at appropriate ages and with adequate skills? Are opportunities available that enable youth to overcome skill mismatches through vocational skills training? Are youth succeeding in finding productive employment and becoming integrated into the labour market?
\end{abstract}

Looking at the current employment situation of youth in Rajasthan, this policy brief argues that significant investment in terms of appropriate policies and programmes are required to improve the employability of youth in the state and thereby enable them to find full and productive employment.

The study

Data are drawn from the Youth in India: Situation and Needs study, a sub-nationally representative study undertaken for the first time in India of key transitions experienced by young people in six states of India, including Rajasthan. The study included a representative survey of youth in both rural and urban settings. Respondents included unmarried women and men and married women aged 15-24 and, in view of the paucity of married men in these ages, married men aged 15-29.

In Rajasthan, the survey was conducted in 2007. A total of 10,002 married and unmarried young men and women were interviewed in the survey. These included 1,886 married young men, 2,129 unmarried young men, 2,603 married young women and 3,384 unmarried young women. This brief is based on data obtained from 2,974 young men and 5,987 young women aged 15-24.

The majority of youth were poorly equipped for employment

Findings from the Youth Study indicate that the majority of youth in the state were poorly equipped for employment for which there is a market demand. Most youth were neither adequately educated nor equipped with vocational skills.

\section{Few had completed secondary education}

Fewer than two in five young men $(38 \%)$ and one in five young women $(18 \%)$ had completed secondary education, increasingly a prerequisite to participate in the labour market in the context of globalisation. ${ }^{\text {de }}$ Indeed, as many as one in ten young men (10\%) and two-fifths of young women $(38 \%)$ had never been to school at all in the state.

\section{Few had acquired vocational skills}

A number of vocational training programmes are available to youth through government, non-government and private organisations. However, findings indicate that just $12 \%$ of young men and $22 \%$ of young women had ever attended a vocational training programme.

a United Nations Development Programme (UNDP). 2000. Millennium Development Goals. United Nations website. Accessed 8 January 2008 at <http://www.un.org/millenniumgoals/goals.html $>$.

b Ministry of Labour and Employment. 2008. National Employment Policy. Accessed 15 October, 2009 at $<$ www.labour.nic.in $>$.

c Planning Commission 2009. Coordinated Action on Skill Development. Accessed on 15 October, 2009 at $<$ http://planningcommission.gov.in/reports/genrep/rep_csa.htm>.

${ }^{d}$ United Nations. 2007. Goals and targets for monitoring the progress of youth in the global economy: Report of the Secretary.

e National Research Council and Institute of Medicine. 2005. Growing up Global: The Changing Transitions to Adulthood in Developing Countries, Washington, D.C.: The National Academies Press. 
Percentage of youth who had ever attended a vocational training programme and who were interested in participating in such programmes

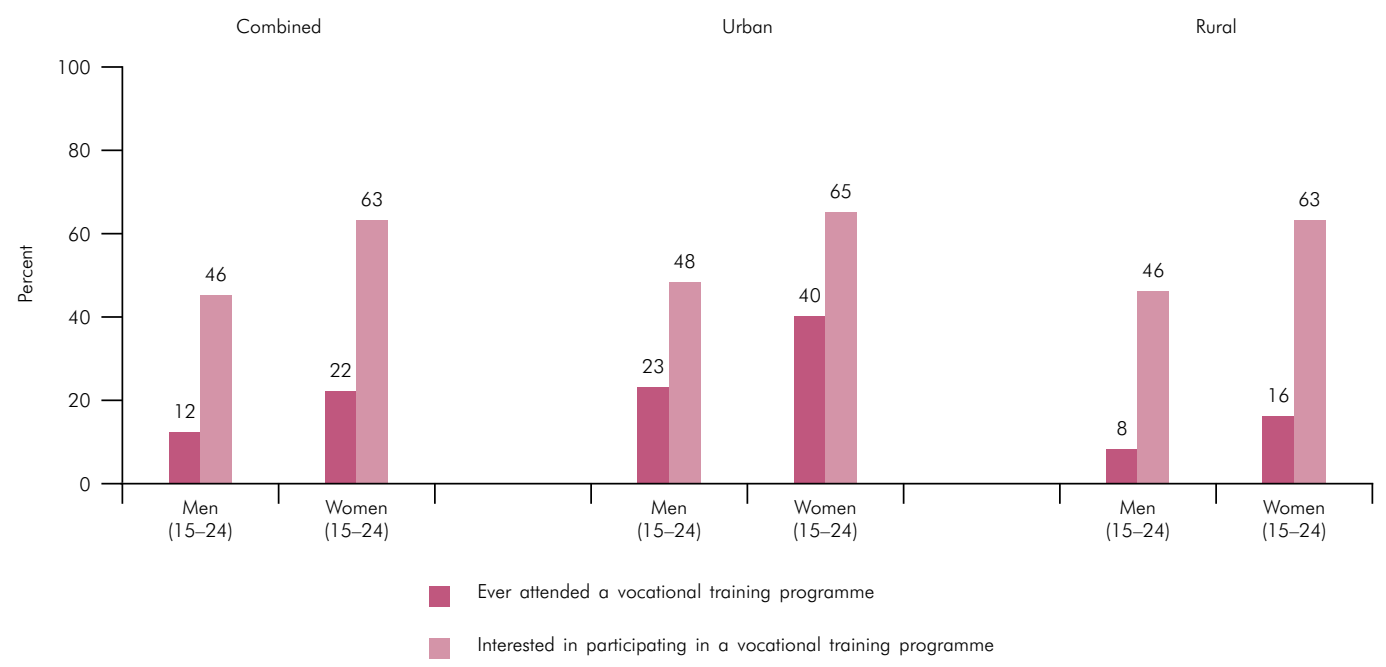

Moreover, findings show that the kind of training received varied by the sex of the respondent. Most young women who had received vocational training had typically acquired traditional skills. For example, 70\% reported training in tailoring and $36 \%$ in handicrafts, painting or embroidery, compared to just $13 \%$ who reported training in computer skills. Young men were far less likely to report training in traditional skills (just $2 \%$ and $6 \%$ reported training in tailoring and crafts, for example). Indeed, among young men, leading training programmes reported included computer skills (48\%), auto mechanics or electrical work (20\%), driving (12\%) and English language, typing or shorthand $(8 \%)$.

Findings also show that large proportions of youth-46\% of young men and $63 \%$ of young women-were interested in acquiring vocational skills. While young men's preferences were focused on computer training, auto mechanics or electrical work, English language, typing or shorthand, and driving, the majority of young women continued to opt for relatively traditional vocational skills, indicating a considerable disconnect between young women's preferences and market needs.

Transition to work roles was not easy or successful for many

Work profiles suggest that three in five young men $(48 \%$ of the unmarried and $93 \%$ of the married) and half of young women (37\% and $58 \%$, respectively) had been engaged in paid or unpaid work at some point in the 12 months preceding the interview. Findings, however, highlight that the transition to work roles is fraught with challenges.

Sizeable numbers transitioned to work roles at young ages

Despite the global recognition that entry into the labour market at young ages competes with young people's schooling opportunities and experiences directly or indirectly, and compromises their productive potential and health, ${ }^{\mathrm{f}}$ and despite significant policy and programme attention to the prevention of early entry into the labour market in India, ${ }^{\mathrm{g}}$ findings indicate that sizeable proportions of youth had transitioned to work roles at young ages. Onefifth $(22 \%)$ of young men and one-third (36\%) of young women reported that they had initiated either paid or unpaid work as children or young adolescents, that is, before age 15. Rural youth were more likely than their urban counterparts to so report. Indeed, rural young women were three times as likely as urban young women to have transitioned to work roles at young ages.

Percentage of youth who had initiated work in childhood or early adolescence (before age 15)

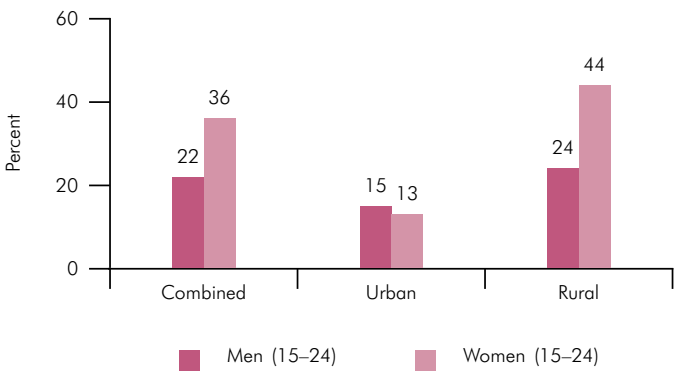

\footnotetext{
${ }^{f}$ National Research Council and Institute of Medicine. 2005. Ibid.

g Ministry of Labour and Employment. 1986. The Child Labour (Prohibition and Regulation) Act 1986, New Delhi: Government of India.
} 


\section{Many young women could not find full time employment}

Findings indicate that among those who had engaged in paid work in the 12 months preceding the interview, many young women could not find full time employment. For example, almost two in five young women (37\%) had worked for less than six months. Moreover, those in rural areas were far more disadvantaged; $41 \%$ of rural young women compared to $23 \%$ of their urban counterparts had worked for less than six months. In contrast, the overwhelming majority of young men $(90 \%)$ had worked for six or more months, and rural-urban differences were narrow among them.

\section{Young men were largely engaged in unskilled non-agricultural activities, young women in agricultural labour}

The majority of youth engaged in remunerated work in the 12 months preceding the interview reported traditional activities; however, leading activities in which they engaged was quite different for young men and women. Almost half of young men were engaged in unskilled non-agricultural activities (45\%), compared to one-quarter of young women (26\%). In contrast, the leading occupation among working young women was agricultural labour (36\%), an occupation reported by just $5 \%$ of working young men. Fewer young men and women (25-28\%) were engaged in skilled non-agricultural activities and just $4-9 \%$ of both young men and women were employed in administrative, executive, managerial or clerical occupations.

\section{Considerable proportions of educated young} people were unemployed

Although unemployment ${ }^{1}$ rates were low among young people (just 6\% among both young men and women) in the state, better educated youth were more likely than others to report unemployment, possibly because of the disconnect between youth skills and market needs. Among young men, for example, unemployment rate increased from $2 \%$ among those with no formal education to $16 \%$ among those who had completed Class 12. Among young women, the rate increased from $2 \%$ among those with no formal education to $14 \%$ among those who had completed $8-11$ years of schooling and $32 \%$ among those who had completed Class 12. These findings suggest that the paucity of opportunities limits the ability of even better qualified youth-young women in particular-to obtain employment.

\section{Many young women were neither in school nor} working

Findings suggest that large proportions of young men and women were either in school or working at the time of the interview and a few were both working and studying. However,

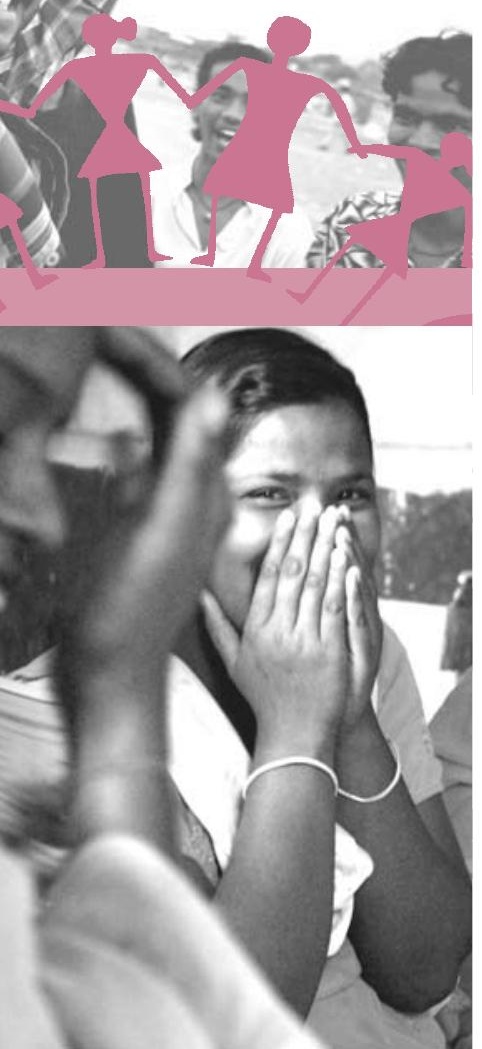

Unemployment rate among youth, according to selected characteristics

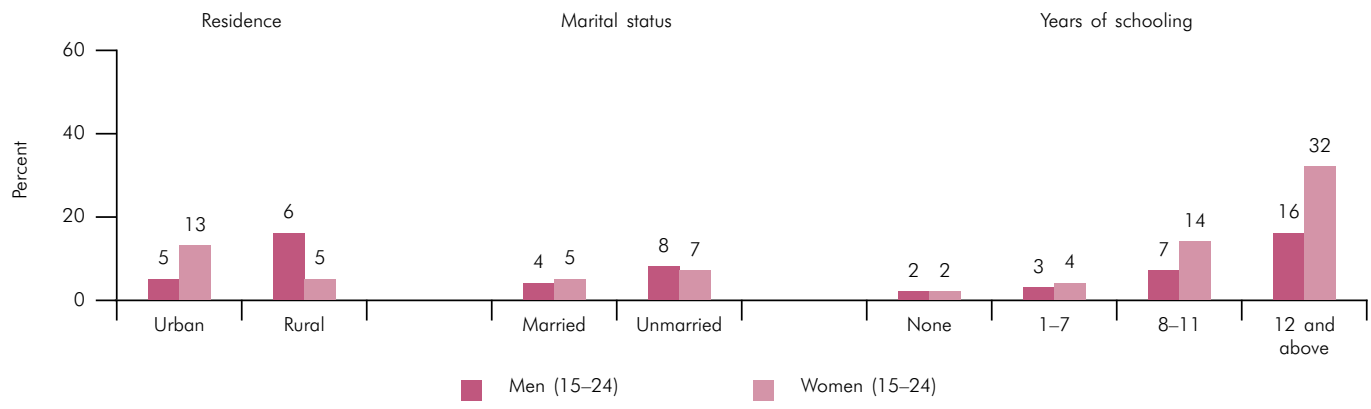

Economic activity and schooling status among youth

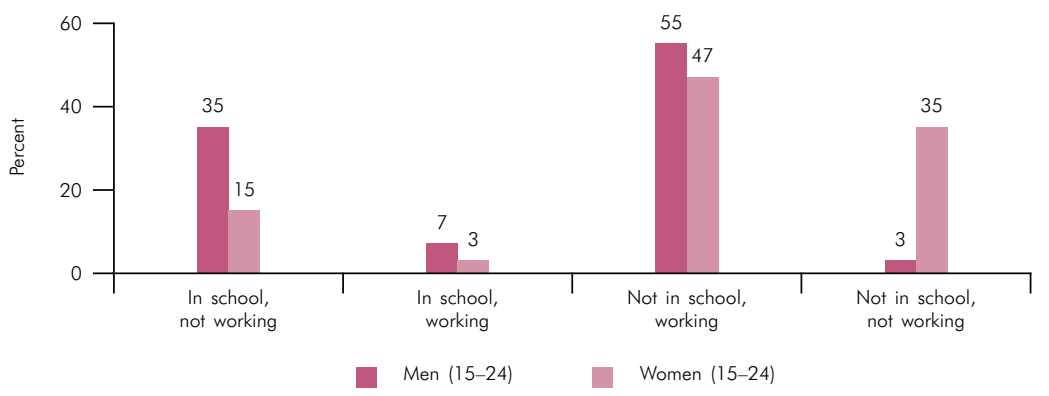

${ }^{1}$ To measure unemployment rates among respondents, the Youth Study assessed (a) whether youth had worked in the 12 months preceding the interview and if so, the number of months worked; and (b) whether youth were seeking work and if so, the number of months during which they had been searching for work. 
